\title{
Variant ataxia-telangiectasia presenting as primary-appearing dystonia in Canadian Mennonites
}

R. Saunders-Pullman, $\mathrm{MD}, \mathrm{MPH}$

D. Raymond, MS

A.J. Stoessl, MD

D. Hobson, MD

T. Nakamura, PhD

S. Pullman, MD

D. Lefton, MD

M.S. Okun, MD

R. Uitti, MD

R. Sachdev, MD

K. Stanley, BS

M. San Luciano, MD

J. Hagenah, MD

R. Gatti, MD

L.J. Ozelius, PhD

S.B. Bressman, MD

Correspondence \& reprint requests to $\mathrm{Dr}$. Saunders-Pullman: rsaunder@bethisraelny.org

Supplemental data at www.neurology.org
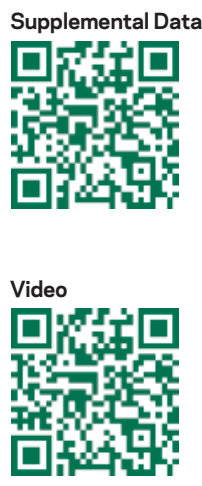

\section{ABSTRACT}

Objective: To compare the phenotype of primary-appearing dystonia due to variant ataxiatelangiectasia (A-T) with that of other dystonia ascertained for genetics research.

Methods: Movement disorder specialists examined 20 Canadian Mennonite adult probands with primary-appearing dystonia, as well as relatives in 4 families with parent-child transmission of dystonia. We screened for the exon 43 c.6200 C >A (p. A2067D) ATM mutation and mutations in DYT1 and DYT6. Clinical features of the individuals with dystonia who were harboring ATM mutations were compared with those of individuals without mutations.

Result: Genetic analysis revealed a homozygous founder mutation in ATM in 13 members from 3 of the families, and no one harbored DYT6 or DYT1 mutations. Dystonia in ATM families mimicked other forms of early-onset primary torsion dystonia, especially DYT6, with prominent cervical, cranial, and brachial involvement. Mean age at onset was markedly younger in the patients with variant A-T $(n=12)$ than in patients with other dystonia $(n=23)$, (12 years vs 40 years, $p<0.05$ ). The patients with $A-T$ were remarkable for the absence of notable cerebellar atrophy on MRI, lack of frank ataxia on examination, and absence of ocular telangiectasias at original presentation, as well as the presence of prominent myoclonus-dystonia in 2 patients. Many also developed malignancies.

Conclusion: Ataxia and telangiectasias may not be prominent features of patients with variant A-T treated for dystonia in adulthood, and variant A-T may mimic primary torsion dystonia and myoclonus-dystonia. Neurology ${ }^{\circledR}$ 2012;78:649-657

\section{GLOSSARY}

$\mathbf{A F P}=\alpha$-fetoprotein; $\mathbf{A}-\mathbf{T}=$ ataxia-telangiectasia; $\mathbf{P D}=$ Parkinson disease.

Ataxia-telangiectasia (A-T) is a rare autosomal recessive disorder due to mutations in the ATM gene, ${ }^{1-3}$ typically presenting with progressive cerebellar dysfunction and unsteady gait in early childhood and often requiring the use of a wheelchair by age 10. A-T may present in milder variant forms, in which the neurologic features are not as rapidly progressive or as severe. Onset is usually in childhood; however, in variant A-T, ocular telangiectasias may not be prominent, and ataxia is more slowly progressive- only mild to moderately severe by adulthood. ${ }^{4-8}$ Movement disorders are usually the presenting feature of variant A-T; up to $40 \%$ of patients have tremor by age $12-34 .^{8}$ Almost all patients with variant A-T had movement disorders by adulthood, including resting tremor or dystonia (60\%) and choreoathetosis (70\%). ${ }^{8}$ Whereas survival into adulthood is more common than in classic A-T, malignancies remain frequent. Neuropathy is almost always a later emerging feature. ${ }^{8}$ Herein, we performed a rigorous crosssectional analysis of the clinical features of variant $\mathrm{A}-\mathrm{T}$ in a cohort of adults with a dystonia-

\footnotetext{
From the Department of Neurology (R.S.-P., D.R., K.S., M.S.L., S.B.B.), Beth Israel Medical Center, New York, NY; Departments of Neurology (R.S.-P., S.B.B.) and Radiology (D.L.), Albert Einstein College of Medicine, Bronx, NY; Department of Neurology (A.J.S.), University of British Columbia, Vancouver, Canada; Department of Neurology (D.H.), University of Manitoba, Winnipeg, Canada; Departments of Pathology and Laboratory Medicine and Human Genetics (T.N., R.G.), Geffen School of Medicine, UCLA, Los Angeles, CA; Department of Neurology (S.P.), Columbia University, New York, NY; Department of Neurology (M.S.O.), University of Florida, Movement Disorders Center, College of Medicine, Gainesville; Department of Neurology (R.U.), Mayo Clinic Jacksonville, Jacksonville, FL; Department of Neurology (J.H.), University of Luebeck, Luebeck, Germany; and Departments of Genetics and Genomic Sciences and Neurology (L.J.O.), Mount Sinai School of Medicine, New York, NY. Study funding: Supported by NIH (NS26636 to S.B.B., K23NS047256 to R.S.-P.), the Bachmann-Strauss Dystonia \& Parkinson Foundation, and the Parkinson's Disease Foundation (to S.P.).
}

Disclosure: Author disclosures are provided at the end of the article. 
predominant phenotype, by comparing these individuals with 23 patients with dystonia without the mutation.

METHODS Standard protocol approvals, registrations, and patient consents. The internal review boards at Beth Israel Medical Center and Columbia University approved this study.

Genetics and molecular methods. In all the multiplex families, dystonia was present in 2 generations and was consistent with a dominant mode of transmission with reduced penetrance (although there was consanguinity in 2 of the families); therefore, testing for mutations in DYT6 and DYT1 was performed. No individuals had ataxia or telangiectasia, and the diagnosis of A-T was not considered until a distant relative in one family was diagnosed with A-T after poor outcome from irradiation of a lymphoid malignancy that began at 3 years of age. He had early balance and walking difficulties, which subsequently improved, as well as dystonia. ${ }^{9}$ We then determined that the homozygous exon 43 c.6200 C>A (p. A2067D) ATM mutation found in this relative was the etiology for the dystonia in the proband of one of the families and therefore screened the other individuals from this family, as well as all other patients and family members to determine whether they shared this A-T mutation. For ATM testing, DNA was extracted using the Puregene procedure (Qiagen, Valencia, CA), followed by targeted screening of the mutation c.6200 C>A (p. A2067D). ${ }^{10}$ A 345-bp product encompassing exon 43 was amplified using the following intronic primers: forward 5'-cacccagctgatattttggga- 3 ' and reverse 5' tgtttagaatgaggagagaggc- $3^{\prime}$. The c.6200 C>A mutation was detected by digestion with HaeIII followed by agarose gel electrophoresis. Sanger sequencing verified all homozygous genotypes and a representative sample of heterozygous carriers. Probands were also screened for mutations in DYT1 and DYT6, as described previously. ${ }^{11,12}$ Radiosensitivity assays and screening for ATM levels were performed in C:301, C:302, and D:301 using methods described previously. ${ }^{13,14}$

Participants and clinical methods. In our study, initially undertaken to identify the DYT6 gene in Amish and Mennonites with dystonia, ${ }^{15,16} 20$ probands with dystonia and with Canadian Mennonite heritage ( 4 from the multiplex families and 16 others) were ascertained through referring movement disorder neurologists and response to research advertisements. Probands and available family members were interviewed and examined in person at family homes or medical centers and videotaped according to previously published protocols ${ }^{17}$ from 1998 to 2010. Blood for DNA extraction was obtained.

Movement disorder neurologists who were blinded to genotype information made final decisions regarding the presence of definite, probable, possible, and no dystonia after considering the evaluations of on-site examiners, video review examiners, and any additional information available from medical records. ${ }^{17}$ Information regarding other movement disorders (e.g., myoclonus, chorea, and parkinsonism) was also noted in the video review.

A total of 156 family members had clinical information and DNA available for analysis, and 35 were definitely affected with dystonia, including 19 individuals from 4 multiplex Canadian Mennonite families (figure 1) and 16 others. All examinations and video reviews were completed as part of dystonia studies before the determination that dystonia was due to a founder A-T mutation in 3 of the families.

Variant A-T. After determination that A-T was the causative disease in families $\mathrm{A}, \mathrm{B}$, and $\mathrm{C}$, reports of telangiectasias and malignancies were ascertained from medical records and follow-up, and 2 individuals from family $\mathrm{C}$ had $\alpha$-fetoprotein (AFP) assessed (C:301 and C:303) and video rereview to assess chorea. Brain pathology reports were available for one subject (family A) and 2 previously deceased family members (from family C). C:301 had extensive testing after the diagnosis of A-T, including neuro-ophthalmologic examination and quantitative motor physiology testing (tremor analysis ${ }^{18}$ and spiral analysis ${ }^{19}$ ).

Statistical analysis. Clinical features of individuals with dystonia homozygous for the $A T M$ c.6200 C > A mutation were compared with those of mutation-negative individuals, using generalized estimating equation models for dichotomous variables and random effects models for continuous or ordinal variables (STATA8; StataCorp, College Station, TX).

RESULTS A total of 35 individuals from 20 families of Canadian Mennonite background with definite dystonia were identified. Nineteen of the individuals with definite dystonia were from 4 multiplex families. The remaining 16 individuals did not have an affected relative examined, although 7 reported a family history suggestive of dystonia.

No individuals harbored either a DYT1 or DYT6 mutation. Twelve subjects with definite dystonia from families A-C harbored homozygous 6200 C $>$ A ATM mutations. Twenty-three others with dystonia were noncarriers (family D and all other affected individuals) (table 1). There was only one additional homozygous carrier among the family members with possible or no dystonia. She had possible right leg dystonia, minimal balance problems, and normal tandem gait on examination at age 8. In addition, her family had noted swaying of her trunk while sitting at 13 months that improved with age. Two families were determined to be related; the third was not.

Clinical features. Among the subjects with dystonia with the $6200 \mathrm{C}>\mathrm{A}$ ATM mutation, most had early age at onset with slowly progressive dystonia and irregular tremor, and some had myoclonus (table 2 and video [on the Neurology ${ }^{\circledR}$ Web site at www.neurology.org]). Movements were compatible with a highly active lifestyle in all. Although some had clumsy gait, none were described as ataxic (table 2). Two mutationpositive subjects reported ataxia in early childhood that remitted.

Age at onset of dystonia was younger in the A-T group (median 12 years, range $1-20$ years) than in the group without A-T (median 40, range 9-59 years) $(p<0.001)$ (figure 2$)$. Site of onset of dystonia did not differ between the 2 groups, with neck onset being most common for both homozygous 
Family A

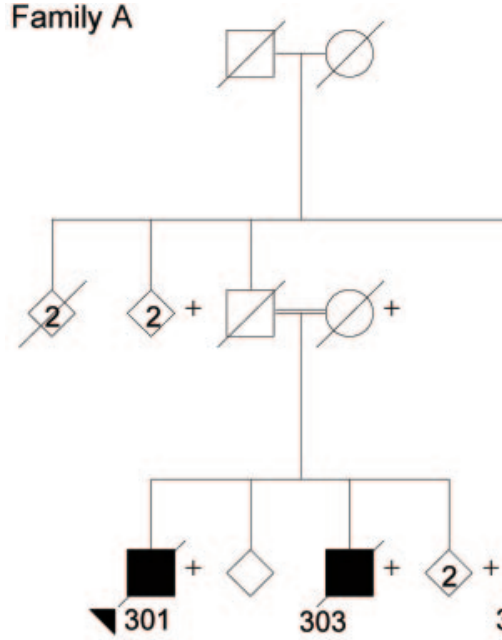

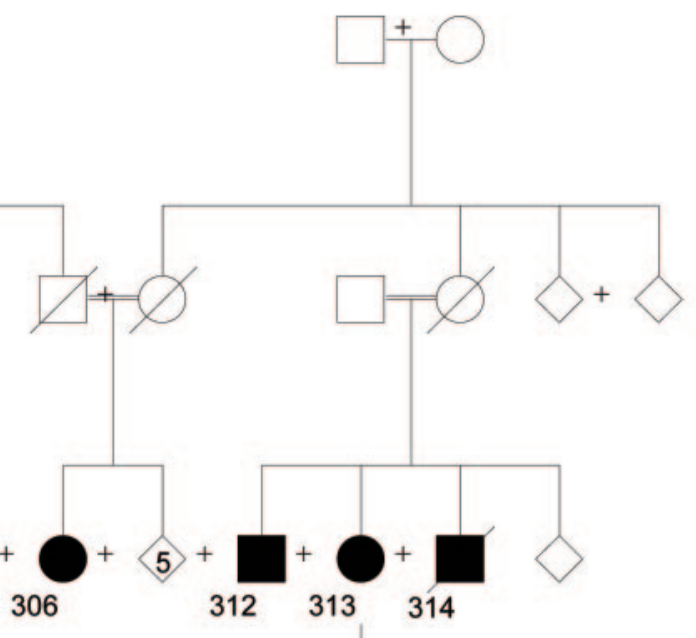

Family B

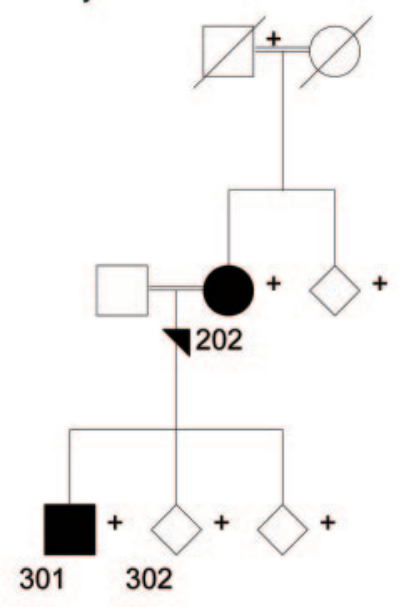

Family C

.
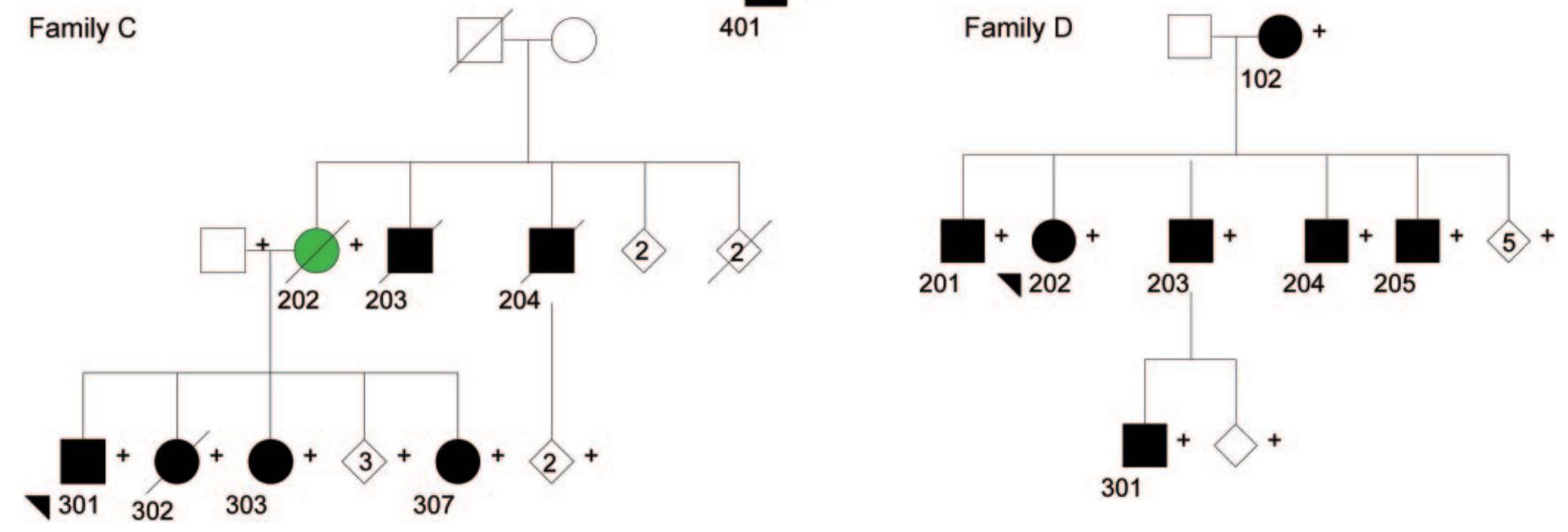

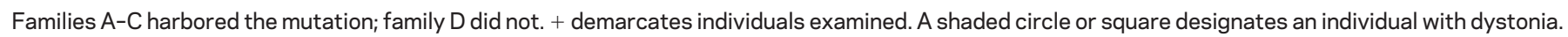
No + indicates individuals affected by history.

mutation carriers and noncarriers. In contrast, final distribution of dystonia varied markedly among groups ( $p=0.03$ ) with that in the mutation group more likely to be generalized $(58.3 \%$ vs $13 \%)$ and $92 \%$ of the homozygous mutation carriers having brachial dystonia, whereas only $26.1 \%$ of noncarriers had arm involvement. Leg dystonia was more frequent in the mutation-positive group, although there was limited functional impairment, as only one individual used a walking aid, and none used a wheelchair.

Cranial involvement was common in both groups (66.7\% in the AT group and $52.2 \%$ in the noncarrier group), but tongue and jaw involvement were different, with $58.3 \%$ of homozygous individuals having dystonia in these sites, compared with only $21.7 \%$ of the noncarriers. Speech was rated as abnormal in $91.7 \%$ of the patients with A-T but in only in
$35 \%$ of the noncarrier patients. Because definite laryngeal, jaw, or tongue dystonia was not noted in all patients with speech involvement, we cannot fully exclude the possibility that, in addition to dystonia, there may be a cerebellar component.

Although dystonia was the primary movement in all patients, nondystonic features were also noted in some and more frequently in the patients with A-T than in the noncarriers. Two of the 12 ATM homozygotes had a phenotype consistent with myoclonusdystonia, whereas none of the mutation-negative subjects did. Facial choreiform movements were also noted in the patients with A-T, although these could also be seen in DYT6 dystonia (video).

Additional clinical features. In all 3 A-T mutation families, there was at least one family member who 


\begin{tabular}{|c|c|c|c|}
\hline \multirow[t]{2}{*}{$\begin{array}{l}\text { Clinical feature } \\
\text { nonmutation } \mathrm{d}\end{array}$} & \multirow[b]{2}{*}{$\begin{array}{l}\text { ATM mutation } \\
\text { cases }(n=12)\end{array}$} & \multirow{3}{*}{$\begin{array}{l}\text { Mutation-negative } \\
(\mathrm{n}=23) \\
69.6\end{array}$} & \multirow[t]{2}{*}{ tion and } \\
\hline & & & \\
\hline Women, \% & 50 & & 0.260 \\
\hline $\begin{array}{l}\text { Age at examination, } y \text {, median } \\
\text { (range) }\end{array}$ & $51.5(12-64)$ & $52.0(23-84)$ & 0.129 \\
\hline $\begin{array}{l}\text { Age at onset, } y \text {, median } \\
\text { (range) }\end{array}$ & $12(1-20)$ & $40(9-59)$ & $<0.01$ \\
\hline \multicolumn{4}{|l|}{ Site onset, $\%^{\mathrm{b}}$} \\
\hline Arm & 25 & 8.7 & 0.208 \\
\hline Leg & 16.6 & 4.3 & 0.248 \\
\hline Cranial & 8.3 & 37.5 & 0.105 \\
\hline Face & 0 & 21.7 & \\
\hline Tongue/jaw & 0 & 0 & \\
\hline Larynx & 8.3 & 4.4 & 1.000 \\
\hline Cervical & 58.3 & 60.9 & 0.884 \\
\hline \multicolumn{4}{|l|}{ Sites affected, \% } \\
\hline Arm & 91.7 & 34.78 & 0.003 \\
\hline Leg & 50.0 & 13.4 & 0.025 \\
\hline Cranial & 66.7 & 52.2 & 0.413 \\
\hline Face & 66.7 & 47.8 & 0.476 \\
\hline Tongue/jaw & 58.3 & 21.7 & 0.059 \\
\hline Larynx & 41.7 & 8.7 & 0.033 \\
\hline Cervical & 83.3 & 73.9 & 0.532 \\
\hline \multicolumn{2}{|l|}{ Distribution, \% } & & 0.017 \\
\hline Focal & 16.6 & 43.5 & 0.126 \\
\hline Segmental & 25.0 & 43.5 & 0.289 \\
\hline Generalized/multifocal & 58.3 & 13.0 & 0.009 \\
\hline Speech affected, \% & 91.7 & 26.1 & 0.008 \\
\hline
\end{tabular}

a All positive vs negative.

b Some individuals had more than one site of onset.
In C:301, quantitative physiologic analysis revealed a low-frequency tremor varying from 3 to 7 $\mathrm{Hz}$, irregular postural, and action tremors of his head and hands, worse on the right side, driven by short and long duration $(100-500 \mathrm{msec})$ proximal neck and cocontracting forearm antagonist EMG bursts. There were infrequent short-duration (25-50 msec) cocontracting EMG bursts in the right forearm antagonists consistent with myoclonus. Computerized spiral analysis revealed mild to moderate overall degrees of severity, worse on the right, with low-frequency $4-5 \mathrm{~Hz}$ irregular multiaxial tremors. Spiral executions were of normal speed, without evidence for micrographia but with mildly increased loop width variability. MRI and transcranial sonography imaging for C:301 is shown in figure 3 .

Four of the ATM homozygotes had improvement of spasms and pain with cervical botulinum toxin A injections. Improvement occurred with anticholinergics (1 subject) and diazepam (3 subjects). No response occurred to baclofen (Lioresal) (1 subject), tetrabenazine (2 subjects), or carbidopa/levodopa (3 subjects).

Evaluation of heterozygous carriers. Among the family members in the dystonia families, 37 individuals (mean \pm SD age $44 \pm 24$ years, range $8-86$ years) carried one copy of the founder mutation. None of the heterozygous carriers demonstrated definite dystonia. One carrier had definite parkinsonism and was subsequently treated with levodopa with improvement. C:201, an obligate carrier, died at the age of 82 without evidence of parkinsonism.

Historical information in families with ATM mutations. C:204 died of a sarcoma at age 51, at which time movements interfered with ambulation. Autopsy did not show cerebellar or brainstem degeneration. C:203 had movements that slowly but progressively worsened with age. Speech was normal until the later phases of illness, and just before death he could walk with great difficulty but was able to drive a car. It is not clear whether the gait difficulty was secondary to neuropathy or ataxia. He died at age 51 from a malignancy of unknown type, and autopsy showed atrophy of the olivary nucleus and a reduction of large Betz cells in the motor cortex. A:314 had arm and neck movements. Of 5 unexamined siblings of C:201 (an obligate carrier) who survived to adulthood, one brother reportedly had levodopa-responsive Parkinson disease (PD) diagnosed at age 42 and died at age 77, another had parkinsonism with prominent postural instability, and a sister had PD and died at age 77.

DISCUSSION Our data suggest that dystonia, especially early-onset dystonia with cervical and brachial 
Table 2 Clinical and testing features in all ATM carriers affected with dystonia

\begin{tabular}{|c|c|c|c|c|c|c|c|c|c|c|c|}
\hline Family & Sex & $\begin{array}{l}\text { Age } \\
\text { exam, y }\end{array}$ & $\begin{array}{l}\text { Age } \\
\text { onset, } y\end{array}$ & $\begin{array}{l}\text { Site } \\
\text { onset }\end{array}$ & $\begin{array}{l}\text { Sites } \\
\text { affected }^{\text {a }}\end{array}$ & $\begin{array}{l}\text { Myoclonus/ } \\
\text { jerky } \\
\text { dystonia }\end{array}$ & Chorea & $\begin{array}{l}\text { Symptomatic } \\
\text { neuropathy }\end{array}$ & $\begin{array}{l}\text { Malignancy } \\
\text { (age, y) }\end{array}$ & $\begin{array}{l}\text { Cellular markers } \\
\text { of } A-T \text { : protein } \\
\text { assay and } \\
\text { radiosensitivity }\end{array}$ & AFP \\
\hline \multicolumn{12}{|l|}{ A } \\
\hline \multirow[t]{2}{*}{$301^{c}$} & M & 64 & 13 & Arm & UFNAMRGL & $\mathrm{N}$ & Cranial & & Stomach (56) & & \\
\hline & & & & & & & & & Prostate (64) & & \\
\hline 303 & M & 56 & 16 & Neck & UFJTNAM & & Cranial & & Renal (51) & & \\
\hline 312 & M & 53 & Unknown & Arm & A & & & & Stomach (36) & & \\
\hline 313 & $\mathrm{~F}$ & 52 & Unknown & Unknown & AMRG & & Cranial & & & & \\
\hline 401 & M & 26 & 15 & Arm & NAMRG & FAM & Cranial & & & & \\
\hline \multicolumn{12}{|l|}{ B } \\
\hline \multicolumn{12}{|l|}{ C } \\
\hline 301 & M & 60 & 1 & Neck, legs & LUFNAMK & $\mathrm{N}$ & $\begin{array}{l}\text { Cranial, } \\
\text { neck, arms }\end{array}$ & Sensorimotor & Prostate (59) & $\begin{array}{l}\text { ATM trace } \\
\text { radiosensitivity }\end{array}$ & $\begin{array}{l}22.6 \mu \mathrm{g} / \mathrm{L} \\
\text { (normal }<6.1 \text { ) }\end{array}$ \\
\hline $302^{a}$ & $\mathrm{~F}$ & 53 & 12 & Neck & LUFTNAG & $\mathrm{N}$ & Arm & & Stomach (58) & $\begin{array}{l}\text { ATM lacking } \\
\text { radiosensitivity }\end{array}$ & $\begin{array}{l}84 \mu \mathrm{g} / \mathrm{L} \\
\text { (normal }<11 \text { ) }\end{array}$ \\
\hline 303 & $\mathrm{~F}$ & 51 & 12 & Neck & UFTNAMR & AN & Cranial & Sensorimotor ${ }^{d}$ & & & \\
\hline $307^{e}$ & $\mathrm{~F}$ & 42 & 4 & $\begin{array}{l}\text { Neck, } \\
\text { larynx }\end{array}$ & UFLNAMR & AUFN & $\begin{array}{l}\text { Cranial, } \\
\text { arm }\end{array}$ & $\begin{array}{l}\text { Sensorimotor } \\
\text { (after vincristine) }\end{array}$ & Lymphoma (40) & & \\
\hline
\end{tabular}

Abbreviations: AFP = $\alpha$-fetoprotein; $\mathrm{A}-\mathrm{T}=$ ataxia-telangiectasia; $\mathrm{A}=$ right arm; $\mathrm{F}=$ lower face; $\mathrm{G}=$ left leg; $\mathrm{J}=$ tongue; $\mathrm{K}=\operatorname{trunk} ; \mathrm{L}=$ larynx; $\mathrm{N}=$ neck; $\mathrm{M}=$ left $\operatorname{arm} ; \mathrm{R}=$ right leg; $\mathrm{U}=$ upper face.

a Medical conditions also included Sjögren syndrome, polyclonal gammopathy, history of leukopenia, positive rheumatoid factor, protein S deficiency and deep vein thrombosis, and renal tubular acidosis.

b Protein assay and radiosensitivity: C:302: cells were found to be lacking in ATM protein and were radiosensitive; C:301: lymphoblastoid cells showed radiosensitivity of 19 (normal range $50 \pm 13$; radiosensitive range $14 \pm 7$ ) and Western blot of ATM protein showed only a trace amount ( $<5$ of wild-type controls on same blots) of ATM protein. For D:301 (no c.6200 C >A mutation), activity was in the normal range.

${ }^{\mathrm{c}}$ Autopsy showed mild loss of Purkinje cells in cerebellum.

d Impaired vibration and joint position sense as well as lower extremity areflexia. EMG/NC at age 43 was reported to be normal and at age 51 showed reduced sensorineural action potentials in the sural, median, and superficial peroneal nerves with normal sensory distal latencies and conduction velocities. There were normal compound muscle action potentials in median and extensor digitorum brevis muscle, but slightly reduced tibial, consistent with axonal sensor-motor polyneuropathy.

e Surgery for congenital shortening of the forearm bones (Keinbock disease).

onset and prominent cranial involvement, is a major feature of variant A-T; it may occur without frank ataxia and may be misdiagnosed in adults with primary-appearing dystonia. Both the age at onset and frequency of cranial involvement in the variant A-T group overlap with that seen in DYT6 dystonia ${ }^{18}$ : median age 12 years vs 14 years and $67 \%$ vs $70 \%$ of individuals with variant A-T and DYT6, respectively. ${ }^{16}$ The phenotype also overlaps with myoclonus-dystonia.

Our subjects differ from those with classic A-T in their overall preserved gait in adulthood and absence of prominent telangiectasias, oculomotor apraxia, and ataxia. ${ }^{3,8,20-25}$ However, ataxia that was present in early childhood and spontaneously remitted was present in 2 individuals, and some individuals had clumsy gait that was not solely attributed to dystonia. Therefore, absence of ataxia does not exclude a diagnosis of variant $\mathrm{A}-\mathrm{T}$, but mild clumsiness, possible ataxic features, childhood history of a remitting ataxia, and family history, even in a dominantappearing transmission pattern, could support a variant A-T diagnosis. Because no subjects had ocular telangiectasias, but oropharyngeal telangiectasias were noted in our subject and in another subject with mild A-T, examination should include thorough evaluation for oropharyngeal telangiectasias, and their presence should heighten the suspicion of A-T.

The presence of parkinsonism in a heterozygous family member as well as in 3 siblings of an obligate carrier and prior reports of rest tremor in variant $A-T,{ }^{8}$ raise the question of whether parkinsonism may be part of a motor phenotype in heterozygous and homozygous A-T mutation carriers. There is selective loss of dopaminergic nigrostriatal neurons in ATM-deficient mice, ${ }^{26}$ and substantia nigra Lewy bodies occurred in a 31-year-old individual with A-T. ${ }^{27}$ Although no nigral cell loss was reported in 
Figure 2 Age at onset in individuals with variant ataxia-telangiectasia (A-T) compared with those with nonmutation primary dystonia

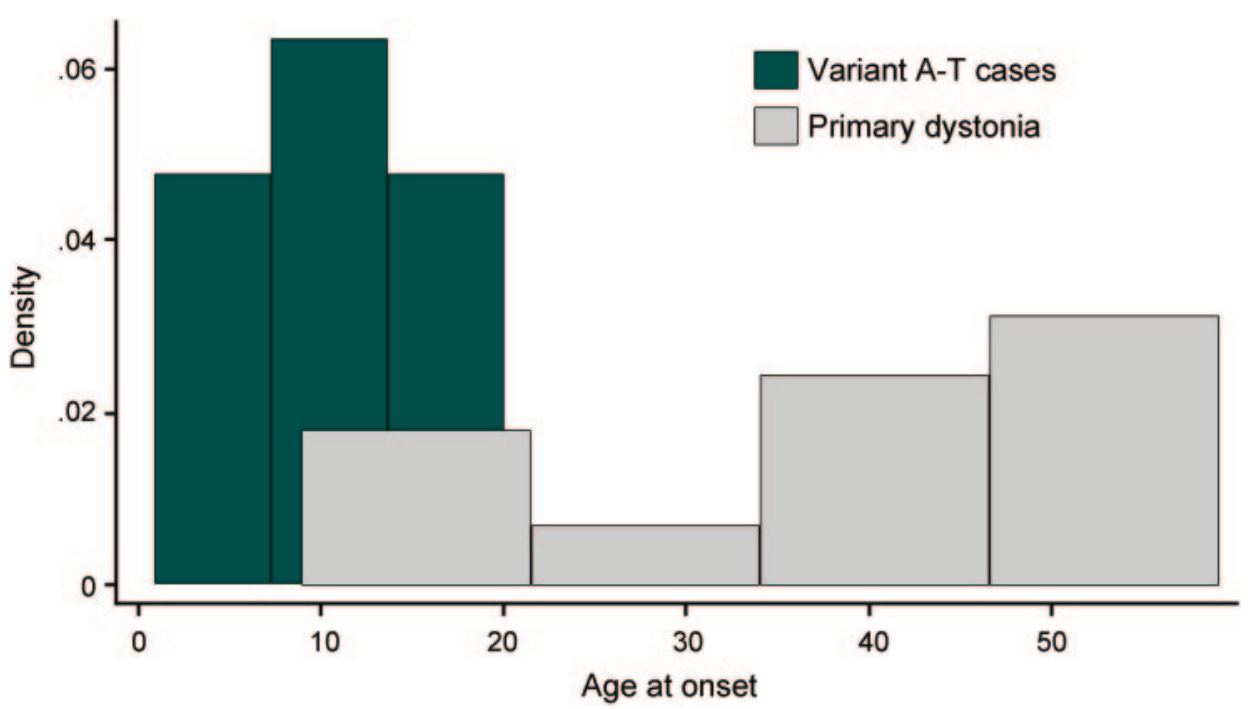

any of the autopsies, there was nigral hyperechogenicity on transcranial sonography in C:301, a nonspecific marker present in $>90 \%$ of individuals with PD that may represent nigral iron deposition. ${ }^{28}$ Substantia nigra hyperechogenicity is also increased in DYT6 dystonia, ${ }^{29}$ although it may be present in $10 \%$ of controls. Parkinsonism in the heterozygous relatives cannot be specifically attributed to abnormalities in $A T M$, as DNA was not available, and $\mathrm{PD}$ is a common disorder. Therefore, it is not clear whether PD relates to the heterozygous ATM mutation, a PD gene segregating in this family, or a chance association.

The etiology of dystonia in both classic and variant A-T is not well understood. Classic A-T is usually caused by null $A T M$ alleles that truncate or severely destabilize the ATM protein, resulting in a lack of functional ATM. ${ }^{30,31}$ ATM protein kinase is a major regulator of multiple signaling cascades that react to and repair DNA strand breaks, and lower levels of ATM may lead to a failure of activation of cellular checkpoints. Consequently, some hypothesize that the clinical presentation may result from faulty DNA repair. ${ }^{5,32}$ The postulated mechanism of variant A-T is that it is due to mutations that result in higher residual levels of ATM protein than those that cause classic A-T. ${ }^{8,31}$ Hence, for homozygous mutations with higher ATM activity, the milder phenotype would tend to segregate within families, and the family as a whole may present with movement disorders rather than ataxia as the primary feature. The pA2067D missense mutation identified in these families (personal communication, T. Nakamura, The Gatti Laboratory, UCLA, 2009) was reported in the heterozygote state in a German patient with A-T (Ae003), ${ }^{10}$ and in the homozy- gous state in Canadian Mennonites.5, Although our families support the idea that variant A-T has a milder phenotype that segregates within families, our data do not fully support the proposed mechanism of milder etiology, because ATM enzyme activity was either very low or nonexistent in the 2 cases studied.

The relationship between decreased ATM activity and prominent dystonia in variant A-T is unclear. Classic A-T occurs with cerebellar and extracerebellar pathology 33,34 and imaging abnormalities, ${ }^{35-37}$ with cerebellar granular and Purkinje cell loss being the most consistent feature. ${ }^{35} \mathrm{MRI}$ examinations in classic A-T revealed, in 1 of 2 patients with prominent movement disorders, obvious basal ganglia pathology $^{37} ; 1$ patient with prominent dystonia had a unilateral putaminal hyperintensity on T2-weighted images and bilateral decreased striatal $\left[{ }^{123} \mathrm{I}\right]$ iodobenzamine binding with SPECT imaging. ${ }^{24}$ It is unlikely that dystonia in variant A-T can be attributed solely to cerebellar atrophy, because this feature was not prominent on MRI in any of our subjects, and in another subject with variant $\mathrm{A}-\mathrm{T}$ with prominent early-onset dystonia, nonspecific cerebellar atrophy without a cerebellar functional correlate was present. ${ }^{22}$ Thus, although the phenotype suggests primary basal ganglia dysfunction with a paucity of cerebellar features, with minimal or no cerebellar atrophy on MRI, the etiology remains uncertain as pathologic findings suggest at least some of the cerebellar involvement noted in classic A-T. With the exception of nigral hyperechogenicity, markers of striatal pathology were also not present on structural imaging in our subjects nor were they noted on autopsy.

Even though neurologic disease is milder overall in variant $\mathrm{A}-\mathrm{T}$ than in classic $\mathrm{A}-\mathrm{T}$, the burden of 


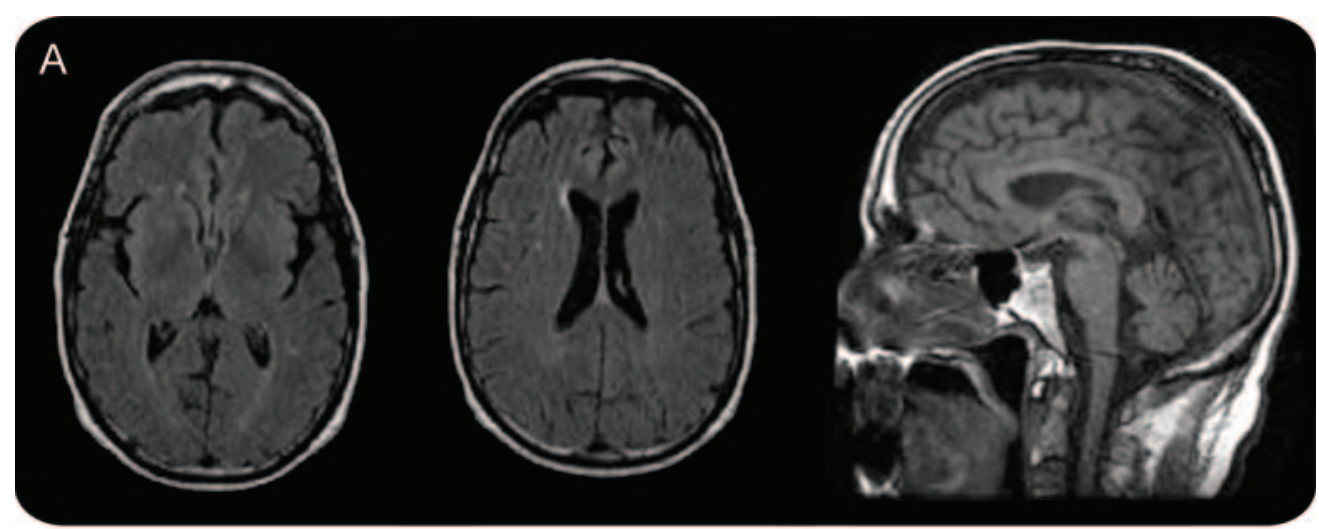

B
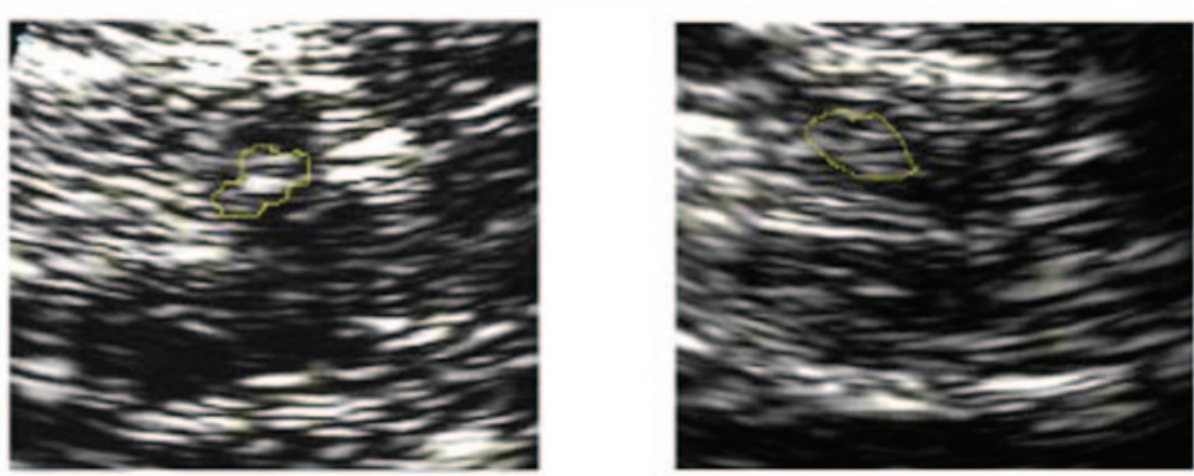

(A) 1.5-T nonenhanced and enhanced MRI of the brain (for C:301) at age 59 revealed several small unidentified bright objects in the white matter of the cerebral hemispheres bilaterally as well as minimal dilatation of the ventricles and subarachnoid spaces consistent with aging, but was otherwise normal, without cerebellar atrophy. After the radiologist was informed of the diagnosis, possible vermian atrophy was noted on rereview. (B) Transcranial sonography of the midbrain: image results for a patient with Parkinson disease (left) and C:301 (right). Yellow encircling demarcates area of hyperechogenicity. In C:301 there was hyperechogenicity compared with laboratory controls. ${ }^{29}$

malignancy remains high. It is therefore imperative to make the diagnosis of variant A-T, because malignancies occur frequently and may be triggered by radiation exposures that might be avoided. Screening for AFP should be considered, and it is elevated (greater than $10 \mathrm{ng} / \mathrm{mL}$ ) in $95 \%$ of individuals with classic A-T. AFP was abnormal in our subjects and a relative, ${ }^{9}$ but at a much lower range than that in classic A-T. Although normal AFP levels can be seen in variant $A-T,{ }^{20} \mathrm{AFP}$ may be a useful low-cost screening tool with excellent sensitivity for A-T and could be followed by immunoblotting for ATM protein and a radiosensitivity assay. ${ }^{5,8,30}$ Gene mutation studies, although supportive, are not necessary for the diagnosis, because mutations are not identified in all patients, and the causality of many missense DNA changes is often elusive. ${ }^{38-40}$ Therefore, AFP screening should be considered in patients with early-onset dystonia, even with normal eye movements and without ataxia or telangiectasia. Our data suggest that not only should A-T be included in the differential diagnosis of early-onset primary-appearing dystonia but also the non-neurologic oncologic disease burden, which may be worsened by radiation, warrants screening for early identification.

\section{AUTHOR CONTRIBUTIONS}

Study design and conceptualization: Dr. Saunders-Pullman, D. Raymond, Dr. Ozelius, Dr. Bressman. Analysis and interpretation of the data: Dr. Saunders-Pullman, D. Raymond, Dr. Stoessl, Dr. Hobson, Dr. Nakamura, Dr. Pullman, Dr. Lefton, Dr. Okun, Dr. Uitti, Dr. Sachdev, K. Stanley, Dr. San Luciano, Dr. Hagenah, Dr. Gatti. Statistical analysis: Dr. Saunders-Pullman. Drafting and revision of the manuscript: Dr. Saunders-Pullman. Revision of the manuscript: D. Raymond, Dr. Stoessl, Dr. Hobson, Dr. Nakamura, Dr. Pullman, Dr. Lefton, Dr. Okun, Dr. Sachdev, Dr. San Luciano, Dr. Hagenah, Dr. Gatti, Dr. Ozelius, Dr. Bressman.

\section{ACKNOWLEDGMENT}

The authors thank all patients and family members who graciously participated in this study; Amber Clark for genotyping and sequencing and Francesca Fike for technical expertise; Dr. Myles Behrens for performing the neuro-ophthalmologic examination; Dr. Rowena Desailly-Chanson, Camille Costan-Toth, and Gary Heiman for help with examining the families and Jeannie Soto-Valencia, Kristina Habermann, and Deborah de Leon for assistance in organizing and coordinating family visits; and Carol Moskowitz for her work in facilitating autopsy, as well as the pathologists at Columbia University and University of British Columbia who performed the autopsies. 


\section{DISCLOSURE}

Dr. Saunders-Pullman serves on the Scientific Advisory Board of the Dystonia Medical Research Foundation; has received research support from the NIH/NINDS (K23NS047256 and K02NS073836), the Michael J. Fox Foundation for Parkinson's Research, the Thomas Hartman Foundation for Parkinson's Research, the Bachmann-Strauss Dystonia \& Parkinson Foundation, and the Marcled Foundation. D. Raymond receives research support from the Michael J. Fox Foundation for Parkinson's Research, the Thomas Hartman Foundation for Parkinson's Research, Inc., and the Marcled Foundation. Dr. Stoessl serves on a scientific advisory board for Biovail Corporation/Medgenesis; has received funding for travel and speaker honoraria from Novartis, Teva Pharmaceutical Industries Ltd., Allergan, Inc., and Abbott; serves on the editorial boards of Annals of Neurology, Lancet Neurology, and Parkinsonism \& Related Disorders; and receives research support from CIHR, the Michael Smith Foundation for Health Research, and the Pacific Alzheimer Research Foundation. Dr. Hobson serves on a scientific advisory board for Parkinson's Society Canada and serves on the editorial board of Parkinsonism and Related Disorders. Dr. Nakamura reports no disclosures. Dr. Pullman serves on scientific boards for Musicians with Dystonia and the Dystonia Medical Research Foundation; serves on the editorial boards of Neurological Bulletin and Tremor and Other Hyperkinetic Movements; holds a patent re: System and method for clinically assessing motor function; conducts motor physiology studies ( $40 \%$ effort), performs intraoperative mapping for deep brain stimulator implantation (20\% effort), administers botulinum toxin (30\% effort), and performs EMG studies ( $10 \%$ effort); receives research support from the NIH, Parkinson Disease Foundation, and the Michael J. Fox Foundation; and receives royalties for technology re: Computerized spiral analysis from Columbia University. Dr. Lefton serves on scientific advisory boards for Ceregene and VasSol, Inc. Dr. Okun serves/has served on scientific advisory boards for the Dystonia Medical Research Foundation and the National Parkinson Foundation and the Medical Advisory Board for the Tourette Syndrome Association; has received funding for travel and speaker honoraria from Medtronic, Inc. prior to 2010; serves on the editorial boards of Parkinsonism and Related Disorders; is a founder of the COMPRESS software used for deep brain stimulation (DBS) screening and has filed patents regarding double lead DBS, DBS targeting, and COMPRESS; receives royalties from the publication of Ultimate Neurology Review (DEMOS, 2007), Parkinson's Disease (Manson, 2009), and Deep Brain Stimulation for Neurological and Psychiatric Diseases (Humana Press, 2009); serves as Medical Director of the National Parkinson Foundation and as a member of the Ask the Expert Forum; and has received research support from Medtronic, Inc. (devices and training fellowship grants), the NIH, the University of Florida Foundation, the Michael J. Fox Foundation, Tyler's Hope for a Dystonia Cure, and the National Parkinson Foundation. Dr. Uitti served as a Continuing Medical Educator for the AAN and serves as an Associate Editor of Neurology ${ }^{\circledR}$; has received research support from Advanced Neuromodulations Systems, the NIH, PARRF, PSG, and Noscira, Inc.; and his institution receives annual royalties from Lundbeck Inc. from the licensing of the technology related to PARK8/LRRK2. Dr. Sachdev was supported from a Fellowship from the Bachmann-Strauss Dystonia \& Parkinson Foundation. K. Stanley reports no disclosures. Dr. San Luciano was funded by an American Academy of Neurology Foundation Award. Dr. Hagenah has received speaker honoraria from GlaxoSmithKline. Dr. Gatti receives research support from the NIH, the Ataxia-Telangiectasia Medical Research Foundation, and the AtaxiaTelangiectasia Ease Foundation. Dr. Ozelius serves on scientific advisory boards for the Dystonia Medical Research Foundation, the BachmannStrauss Dystonia \& Parkinson Foundation, the Benign Essential Blepharospasm Research Foundation, and the National Spasmodic Dysphonia Association; is listed as an author on patents re: Torsin, Torsin genes and methods of use, and Nucleic acids, methods and kits for the diagnosis of DYT6 primary torsion dystonia; receives research support from the NIH, the Dystonia Medical Research Foundation, and the Bachmann Strauss Dystonia \& Parkinson Foundation; and receives royalties from Athena Diagnostics, Inc. for a patent re: Torsin, Torsin genes and methods of use. Dr. Bressman serves on scientific advisory boards for the Bachmann Strauss Dystonia \& Parkinson Foundation, the Michael J. Fox Foundation for Parkinson's Research, and the Dystonia Medical Research Foun- dation; holds a patent re: THAP1 gene testing; and receives research support from the NIH and the Michael J. Fox Foundation for Parkinson's Research.

Received April 4, 2011. Accepted in final form October 26, 2011.

\section{REFERENCES}

1. Gatti RA, Berkel I, Border E, et al. Localization of an ataxia-telangiectasia gene to chromosome 11q22-23. Nature 1988;336:577-580.

2. Savitsky K, Bar-Shira A, Gilad S, et al. A single ataxia telangiectasia gene with a product similar to PI-3 kinase. Science 1995;268:1749-1753.

3. Chun HH, Gatti RA. Ataxia-telangiectasia, an evolving phenotype. DNA Repair 2004;3:1187-1196.

4. Gatti RA. Ataxia-telangiectasia. In: Scriver CR, Beaudet AL, Sly WS, Valle D, eds. The Metabolic and Molecular Bases of Inherited Disease, 8th ed. New York: McGrawHill; 2001:705-732.

5. Gatti R. Ataxia-telangiectasia. In: Pagon RA, Bird TC, Dolan CR, Stephens K, eds. GeneReviews [Internet]. Seattle, WA: University of Washington, Seattle; 1993-1999 Apr 14 (updated 2010). PMID: 20301790.

6. Dork T, Bendix-Walters R, Wegner RD, Stumm M. Slow progression of ataxia-telangiectasia with double missense and in frame splice mutations. Am J Med Genet A 2004; 126A:272-277.

7. Alterman N, Fattal-Valevski A, Moyal L, et al. Ataxiatelangiectasia: mild neurologic presentation despite null ATM mutation and severe cellular phenotype. Am J Med Genet A 2007;143A:1827-1834.

8. Verhagen MM, Abdo WF, Willemsen MA, et al. Clinical spectrum of ataxia-telangiectasia in adulthood. Neurology 2009;73:430-437.

9. Yanofsky RA, Seshia SS, Dawson AJ, et al. Ataxiatelangiectasia: atypical presentation and toxicity of cancer treatment. Can J Neurol Sci 2009;36:462-467.

10. Sandoval N, Platzer M, Rosenthal A, et al. Characterization of ATM gene mutations in 66 ataxia-telangiectasia families. Hum Mol Genet 1999;8:69-79.

11. Ozelius LJ, Hewett JW, Page CE, et al. The early-onset dystonia gene encodes an ATP-binding protein. Nat Genet 1997; 17:40-48.

12. Fuchs T, Gavarini S, Saunders-Pullman R, et al. Mutations in the THAP1 gene are responsible for DYT6 primary torsion dystonia. Nat Genet 2009;41:286-288.

13. Sun X, Becker-Catania SG, Chun HH, et al. Early diagnosis of ataxia-telangiectasia using radiosensitivity testing. J Pediatr 2002;140:724-731.

14. Chun HH, Sun X, Nahas SA, et al. Improved diagnostic testing for ataxia-telangiectasia by immunoblotting of nuclear lysates for ATM protein expression. Mol Genet Metab 2003;80:437-443.

15. Saunders-Pullman R, Raymond D, Senthil G, et al. Narrowing the DYT6 region and evidence for locus heterogeneity in the Amish-Mennonites. Am J Med Gen 2007; 143A:2098-2105.

16. Bressman SB, Raymond D, Fuchs T, Heiman GA, Ozelius LJ, Saunders-Pullman R. THAP1 (DYTG) mutations in early-onset primary dystonia. Lancet Neurology 2009;8: 441-446.

17. Bressman SB, de Leon D, Brin MF, et al. Idiopathic dystonia among Ashkenazi Jews: evidence for autosomal dominant inheritance. Ann Neurol 1989;26:612-620. 
18. Hsu AW, Piboolnurak PA, Floyd AG, et al. Spiral analysis in Niemann-Pick disease type C. Mov Disord 2009;24: $1984-1990$

19. Saunders-Pullman R, Derby C, Stanley K, et al. Validity of spiral analysis in early Parkinson's disease. Mov Disord 2007;23:531-537.

20. McConville CM, Stankovic T, Byrd PF, et al. Mutations associated with variant phenotypes in ataxia-telangiectasia. Am J Hum Genet 1996;59:320-330.

21. Saunders-Pullman R, Gatti R. Ataxia-telangiectasia: without ataxia or telangiectasia? Neurology 2009;73:279-286.

22. Carrillo F, Schneider SA, Taylor AM, Srinivasan V, Kapoor R, Bhatia KP. Prominent oromandibular dystonia and pharyngeal telangiectasia in atypical ataxia telangiectasia. Cerebellum 2009;8:22-27.

23. Bodensteiner JB, Goldblum RM, Goldman AS. Progressive dystonia masking ataxia in ataxia-telangiectasia. Arch Neurol 1980;37:464-465.

24. Koepp M, Schelosky L, Cordes I, Cordes M, Poewe W. Dystonia in ataxia-telangiectasia: report of a case with putaminal lesions and decreased striatal $\left[{ }^{123} \mathrm{I}\right]$ iodobenzamine binding. Mov Disord 1994;9:455-459.

25. Stell R, Bronstein AM, Plant GT, Harding AE. Ataxiatelangiectasia: a reappraisal of the ocular motor features and their value in the diagnosis of atypical cases. Mov Disord 1989;4:320-329.

26. Eilam R, Peter $Y$, Groner $Y$, Segal M. Late degeneration of nigro-striatal neurons in $A T M[/]$ mice. Neuroscience 2003;121:83-98.

27. Agamanolis DP, Greenstein JL. Ataxia telangiectasia: report of a case with Lewy bodies and vascular abnormalities within cerebral tissue. J Neuropathol Exp Neurol 1979;38:475-489.

28. Behnke S, Schroeder U, Dillmann U, et al. Hyperechogenicity of the substantia nigra in healthy controls is related to MRI changes and to neuronal loss as determined by F-Dopa PET. Neuroimage 2009;47:1237-1243.

29. Saunders-Pullman R, Stanley K, Brüggemann N, et al. Substantia nigra hyperechogenicity in DYT6 dystonia: a pilot study. Parkinsonism Relat Disord 2010;16:420422.

30. Chun HH, Gatti RA. Ataxia-telangiectasia, an evolving phenotype. DNA Repair 2004;3:1187-1196.

31. Taylor AM, Byrd PJ. Molecular pathology of ataxia telangiectasia. J Clin Pathol 2005;58:1009-1015.

32. Bakkenist CJ, Kastan MB. DNA damage activates ATM through intermolecular autophosphorylation and dimer dissociation. Nature 2003;412:499-506.

33. Aguilar MJ, Kamoshita S, Landing BH, Boder E, Sedgwick RP. Pathological observations in ataxia-telangiectasia: a report of five cases. J Neuropath Exp Neurol 1968;27: 656-676.

34. de Leon GA, Grover WD, Huff DS. Neuropathologic changes in ataxia telangiectasia. Neurology 1976;26:947951

35. Demaerel PH, Kedall BE, Kingsley D. Cranial CT and MRI in diseases with DNA repair defects. Neuroradiology 1992;34:117-121.

36. Farina L, Uggetti C, Ottolini A. Ataxia telangiectasia: MR and CT findings. J Comput Assist Tomogr 1994;18:724727.

37. Kieslich M, Hoche F, Reichenbach J, et al. Extracerebellar MRI-lesions in ataxia-telangiectasia go along with deficiency of the GH/IGF-1 axis, markedly reduced body weight, high ataxia scores and advanced age. Cerebellum 2010;9:190-197.

38. Perlman SL. Ataxias. Clin Geriatr Med 2006;22:859877.

39. Tavtigian SV, Oefner PJ, Babikyan D, et al. Rare, evolutionarily unlikely missense substitutions in ATM confer increased risk of breast cancer. Am J Hum Genet 2009;85: 427-446.

40. Mitui M, Nahas SA, Du LT, et al. Functional and computational assessment of missense variants in the ataxiatelangiectasia mutation $(A T M)$ gene: mutations with increased cancer risk. Hum Mutat 2009;30:12-21.

\section{Refresh Your Annual Meeting Experience with New 2012 AAN On Demand}

- More than 600 hours of cutting-edge educational content and breakthrough scientific research

- Online access within 24 hours of end of program

- Mobile streaming for most iPad ${ }^{\circledR}$, iPhone ${ }^{\circledR}$, and Android ${ }^{\circledR}$ devices

- USB Flash Drive offers convenient offline access (shipped after the Annual Meeting)

- Enhanced browser, search, and improved interface for better overall experience

Get a great value with special pricing on AAN On Demand and the Syllabi on CD. Pre-order and save up to $\$ 1,200$ ! Learn more at www.aan.com/view/ondemand2. 